\title{
PHYTO AMALGAMATION OF ZINC NANOPARTICLES AND ASSESSMENT OF ITS PHYSICAL PROPERTY AND INVADING ACTIVITY ON ISOLATES OF URINARY TRACT INFECTIONS
}

\author{
ANWER M AND KUMAR A* \\ Department of Biotechnology, Faculty of Engineering \& Technology, Rama University Uttar \\ Pradesh, Kanpur - 209217, India
}

* Corresponding author: E Mail address: ajaymtech@gmail.com; (Ajay Kumar), Mob. No: $+91-9412883081$

Received $19^{\text {th }}$ July 2019; Revised $4^{\text {th }}$ Oct. 2019; Accepted $3^{\text {rd }}$ Jan. 2020; Available online $1^{\text {st }}$ May 2020 https://doi.org/10.31032/IJBPAS/2020/9.5.5105

\begin{abstract}
Urinary tract infections has been a common amongst all nosocomial infections. Indwelling catheters pose greater vulnerability of to the patients to suffer or get imposed to Urinary tract infections. Nanoparticles have imposed varied and specific antibacterial effects in several patients. Considering this thought the research was preceded for phyto amalgamation Zinc Oxide Nanoparticle. Catheters with Zinc Oxide Nanoparticles may prevent the upcoming risk of contamination through microbes and associated infections. The antibacterial effects of Zinc nanoparticles was therefore studied and was found that $22 \mathrm{~mm}$ of ZOI for Pseudomonas aeruginosa, $17 \mathrm{~mm}$ for K. pneumoniae $15 \mathrm{~mm}$. The minimum inhibitory concentration ranged from $150 \mathrm{micrograms} / \mathrm{ml}$ to $250 \mathrm{microgram} / \mathrm{ml}$. The zinc oxide nanoparticles were phyto amalgamated and were characterized to be of size 50-100 nm.
\end{abstract}

Keywords: Urinary Tract Infections, Zinc Oxide nanoparticles, Phyto - amalgamation INTRODUCTION

Urinary tract infections (UTI) are expressed the most widely recognized sort of as most extensive type of infections Urinary emergency clinically provided or nosocomial tract contaminations (UTI) are believed to be infections. Prolonged use of urinary catheters 
builds the danger of getting infected and prompts the emergence of Urinary Tract Infection. Catheter related urinary tract diseases represent somewhat equivalent to $40 \%$ of all medical hospital acquired infections [1] and are brought about by both Gram negative and positive microscopic organisms just as by certain fungi [2]. One of the serious issues related with the treatment of UTI is the arrangement of biofilms on the catheter surfaces. The biofilm on the outside of catheters passes on an endurance bit of leeway to the microorganisms related with it and, in this manner, biofilm on urinary catheters brings about determined contaminations that will in general be impervious to antimicrobial treatment and accordingly non ending infections [3]. The morphology of these singled cell microorganisms allow them to agglomerated the biofilms are significantly not the same as the planktonic microbes displaying protection from antibacterial operators and along these lines making the treatment difficult $[4,5]$. E. coli represents up to $90 \%$ of all UTIs and hazard factors for UTIs incorporate host conduct in patients and have bacterial characteristics. It is accepted that they are adjusted to colonize the urinary tract by creating different adhesins and afterward produce alignment (biofilm) of harmfulness factors. The nearness of destructiveness factors, for example, adhesins communicating E. coli have been demonstrated to be related with a multiplying of the danger of a second UTI, proposing it's conceivable relationship with intermittent or interminable UTI [5]. One of the significant confusions related with catheter related urinary tract disease (CAUTI) is the advancement of biofilm on the catheter which restrains powerful grouping of medication to eliminate bacterial cells. Antigen 43 (Auto transporter protein of) is a self-perceiving adhesins, has a demonstrated job in bury species biofilm formation. Antigen 43 (Ag 43) articulations can drive the arrangement of biofilms comprising of $E$. coli and Pseudomonas fluorescens [6]. The blend of both numerous medication obstruction and the nearness of destructiveness elements can additionally confuse the result of malady. Staphylococcus aureus is another bacterium which is likewise famous for causing UTIs like E. coli $[7,8]$.

Nanotechnology is an emerging stream of science which has already undergone multilevel of developments, the branch manages to ensure the exploitation of amalgamation and coalesced products of size $1-100 \mathrm{~nm}$ named as the nanoparticles or nanomaterials. Nanotechnology may likewise 
be expressed as field of science, which includes the utilization of science and innovation to make new sorts of materials at nanoscale level or materials with nanoscale measurement. These nanomaterials or nanoparticles are delegated natural and inorganic materials Albrecht et al. [1-3].

The combination and utilization of the metal and metal oxide nanoparticles has pulled in the consideration in different fields of science including the clinical, physical, compound, optical, mechanical, and the designing science. These fields of science are engaged with building up the procedures to test and control the single particles and atoms. These metal oxide nanoparticles has a few entrancing and fascinating properties, for example, attractive, electronic, reactant and antimicrobial movement due their high surface zone and high portion of particles. The properties of nanoparticles rely upon the size, shape, sythesis, morphology, and crystalline period of that particular nanoparticle, Cautauro et al., [4-7].

The metal and metal oxides nanoparticles were customarily blended by a few physical and substance strategies including nonsputtering strategy, sol-gel system, and electrochemical method Krishna et al., [811]. These techniques were seen as exorbitant, lethal, required high vitality and weight, were conceivably dangerous and they were hard to isolate [12] Consequently there was a need to build up an increasingly compelling and productive strategy to incorporate the nanoparticles and afterward the natural technique for union appeared which included the utilization of plant and there subsidiary and organisms too [13-16] The utilization of plants and their subsidiaries for nanoparticle combination is a novel methodology since it is ecoaccommodating and practical system Bhaina [17]. The green union system to create nanoparticles is quickly developing among the scientists due to the utilization of less harmful synthetic substances, simple accessibility, safe to deal with, have expansive reasonability of metabolites and most significant one stage blend of nanoparticles Sundrarajan et al. [18-20]. The primary phytochemicals of the plants, which are answerable for the union, incorporates flavones, ketones, terpenoids, aldehydes, amides and so forth. Saxena et al. [21-22]. There are a few assortments of the metal and metal oxide nanoparticles among them zinc oxide nanoparticles have wide applications. The Zinc Oxide nanoparticles are viewed as mechanically significant material due to its wide range application in various fields of innovation with the way things are utilized as 
semiconductor, attractive material, electroluminescent material, thermoelectric material, gas sensor and constituents of the corrective things [23]. Zinc oxide $(\mathrm{ZnO})$ nanoparticles likewise discover its application in natural issues, for example, they are useful in the decrease of dangerous and unsafe synthetic concoctions from condition [24]. Zinc oxide nanoparticles are broadly utilized for the expulsion of arsenic and Sulfur from the water source [25]. Zinc oxide nanoparticles have some striking applications in the diagnostics, microelectronics, and biomolecular identification and so on. They additionally have some valuable applications in the field of medication, for example, they are useful in tranquilize conveyance, finding of infection and have some organic action, for example, antimicrobial and antibacterial action.

\section{MATERIALS AND METHODS}

\section{Synthesis of the Zinc Oxide (ZnO) Nanoparticles}

For the synthesis of the Zinc Oxide nanoparticles $0.02 \mathrm{M}$ aqueous solution of the Zinc Acetate dihydrate was added in $50 \mathrm{ml}$ of the distilled water in Erlenmeyer flask under vigorous stirring. The stirring was continued for 10 minutes after this oscimum sanctum leaf extract was added to the flask. The flask was then loaded with $2.0 \mathrm{M}$ of the $\mathrm{NaOH}$ solution to make the $\mathrm{pH}$ up to 12 . The flask was kept on magnetic stirrer for 2 hours this caused the formation of white precipitate of Zinc oxide. The precipitate was collected and repeatedly washed with distilled water and with ethanol to remove the impurities from it. Finally the Zinc Oxide nanoparticle was obtained by drying the precipitate at $60^{\circ} \mathrm{C}$ [26]. The above process was repeated for different oscimum sanctum leaf extract to obtain different type of the nanoparticles of zinc oxide.

\section{Characterization of the Nanoparticles:}

Scanning electron microscopy (SEM) and Transmission Electron microscopy were the techniques to study the outer structure of Synthesized Nanoparticles by oscimum sanctum as a reducing agent [30].

The integrated zinc oxide nanoparticles were explained for their morphological characters on various premise. The shape and size of nanoparticles was broke down through Scanning Electron Microscopy (SEM). The nanoparticles were then exposed to X-beam (XRD) diffraction investigation to evaluate the crystallinity of the nanoparticles. The average size of crystalline Zinc oxide Nanoparticle that were synthesized with the methanolic extricate of Zinc Nanoparticle were determined by X-ray Diffraction, (XRD) (using a Shimadzu D6000 model) and 
was put under equation using the DebyeScherrer formula. The X-RD was equipped with $\mathrm{Cu} \mathrm{K} \alpha$ radiation sources using the $\mathrm{Ni}$ as a filter. The instrument was provided initial reading of $40 \mathrm{kV} / 30 \mathrm{~mA}$, with $\lambda$ in 1,54060 Å. All X-RD data further were conjoined under the same experimental condition, with an angular range $\left[20^{\circ} \leq 2 \theta \leq 60^{\circ}\right]$.

\section{Disk Diffusion Method}

The antimicrobial suppression characteristics of synthesized $\mathrm{Zn}$ oxide Nanoparticles against the selected isolates were carried out using Kirby-Bauer Disk Diffusion Susceptibility Test method [32]. The bacterial strains selected for the study were spread with the help of glass spreader sterilized by flame over heat. The disk in the phenomena were made with filter paper. The disks were loaded with $10 \mu \mathrm{L}$ of oscimum sanctum extract, Positive control (Antibiotics sure for isolate), and solution containing Nanoparticles dissolved in methanol. The disks were then placed on the agar plate and incubated at $37^{\circ} \mathrm{C}$ for $24 \mathrm{~h}$. The zone of inhibition was observed after $24 \mathrm{~h}$ of incubation.

Minimum Inhibitory Concentration (MIC) and Minimum Bactericidal Concentration (MBC) Evaluation

The MIC and MBC of phyto amalgamated Zinc Nanoparticle were performed utilizing the technique clarified and gave by the rules of CLSI (2012). The MIC test was acted in 96-well round base microtiter plate utilizing standard stock microdilution strategies while the MBC test was performed on the MHA plates. The bacterial inoculums were changed in accordance with the grouping of $10^{6}$ $\mathrm{CFU} / \mathrm{mL}$. For the MIC test, $100 \mu \mathrm{L}$ of the Zinc oxide nanoparticle stock arrangement $(500 \mu \mathrm{g} / \mathrm{mL})$ was included and weakened twofold with the bacterial inoculums in 100 $\mu \mathrm{L}$ of $\mathrm{MHB}$ began from segment 12 to section 3. Section 12 of the microtiter plate contained the most noteworthy convergence of Zinc Oxide Nanoparticle while segment 3 contained the least fixation. Segment 1 filled in as negative control (just medium) and the segment 2 filled in as positive control (medium and bacterial inoculums). Each well of the microtiter plate was included with 30 $\mu \mathrm{L}$ of the Resazurin arrangement and hatched at $37^{\circ} \mathrm{C}$ for $24 \mathrm{~h}$. Any shading changes were watched. Blue/purple shading showed no bacterial development while pink/dreary demonstrated bacterial development. The MIC esteem was taken at the most minimal centralization of antibacterial specialists that represses the development of microbes (shading stayed in blue).

The MBC was defined as the lowest concentration of the antibacterial agents that 
completely kill the bacteria. MBC test was performed by plating the suspension from each well of microtiter plates into MHA plate. The plates were incubated at $37^{\circ} \mathrm{C}$ for $24 \mathrm{~h}$. The lowest concentration with no visible growths on the MHA plate was taken as $\mathrm{MBC}$ value.

\section{RESULTS AND DISCUSSIONS}

Scanning Electron Microscopy and Transmission Electron microscopy of Zinc

\section{Oxide Nanoparticle:}

Figure 1, shows the Scanning Electron Microscope (SEM) image of the zinc oxide nanoparticles under lower magnification and it shows that the particles are agglomerated and complete separation is not occurred. SEM image at higher magnification and we can see that the particles are held together because of weak physical forces. Here particles were formed with size in the nano range therefore it shows that green coalescence by oscimum sanctum as a reduction source is the best way to synthesize nanoparticles.

\section{Transmission electron microscopy:}

TEM images (Figure 2a, 2b) of phyto amalgamated Zinc oxide Nanopartickes revealed the cubical and small nature of nanoparticles ranging from the size of $40 \mathrm{~nm}$ to $90 \mathrm{~nm}$. Polydispersed nature of nanoparticle was observed they were in direct contact with each other as observed by [13]. The agglomeration of size of nanoparticle was due to conjoining of nanoparticles of $10-100 \mathrm{~nm}$ sizes together at the time of evaporation by solvent. The oscimum sanctum is already known as antibiotic [29].

The Figure (2a 2b) represents Transmission electron microscopy of the phyto amalgamated Zinc Oxide Nanoparticles The first slot size observe was $150 \mathrm{~nm}$ and the second slot observed was $55 \mathrm{~nm}$.

\section{X-Ray Diffraction (XRD)}

The XRD of the incorporated zinc oxide shows expansive tops at estimations of 31.9, $34.5,36.3,56.7$, and 62.9 which are common for the zinc oxide structure. Striking line expanding of the diffraction tops means that the combined materials are in nanometre run. The normal molecule size has been resolved from full width at half greatest (FWHM) of the diffraction tops utilizing Scherrer's condition. Which is given as $\mathrm{t}=0.93 /(\mathrm{B} \cos$ s) where 3 is the frequency of $\mathrm{x}$-beam and $\mathrm{B}$ is the full width at half most extreme. The normal molecule size of zinc oxide nanoparticles has been seen as $25 \mathrm{~nm}$ (Figure 3).

Antibacterial activity against Pathogens of Urinary tract infection 
The isolates of Urinary Tract infections obtained were Klebsiella pneumoniae, Pseudomonas aeruginosa and Proteus morganii. The isolates chosen were multi drug resistance. Oscimum sanctum methanolic extract was capable to provide zone of inhibition of 14 against Pseudomonas aeruginosa, $12 \mathrm{~mm}$ against Klebsiella pneumoniae and $16 \mathrm{~mm}$ against Proteus morganii. The zinc nanoparticle gave Zone of inhibition of about $15 \mathrm{~mm}$ for Pseudomonas aeruginosa $17 \mathrm{~m}$ for Klebsiella pneumoniae and $22 \mathrm{~mm}$ for Proteus morganii.

\section{Minimum Inhibitor Concentration}

The MIC value obtained for Klebsiella pneumoniae for oscimum sanctum extract was $(>=150 \mu \mathrm{g} / \mathrm{ml})$ for Zinc Oxide nanoparticle it was observed to be $(>=100$ $\mu \mathrm{g} / \mathrm{ml})$; For Pseudomonas aeruginosa, oscimum sanctum extract gave minimum inhibitory concentration of $(>=250 \mu \mathrm{g} / \mathrm{ml})$. Similar results were observed by [30-31].

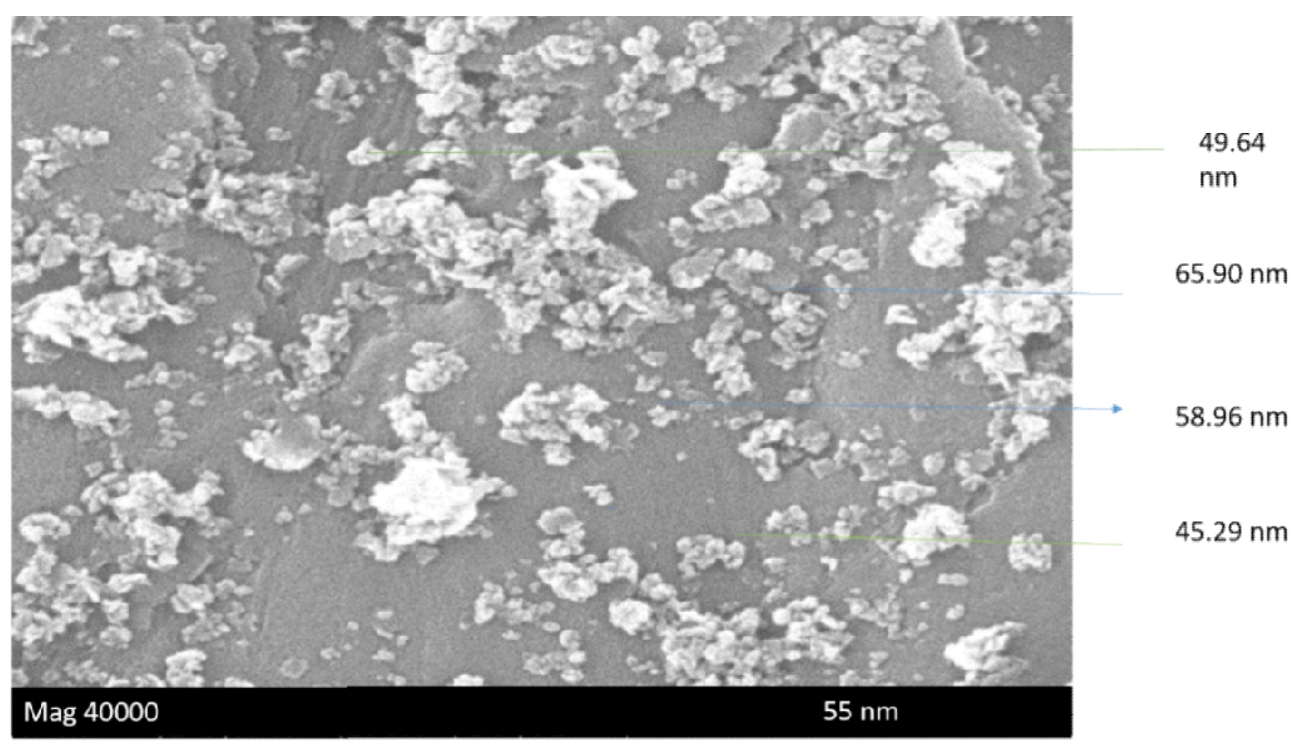




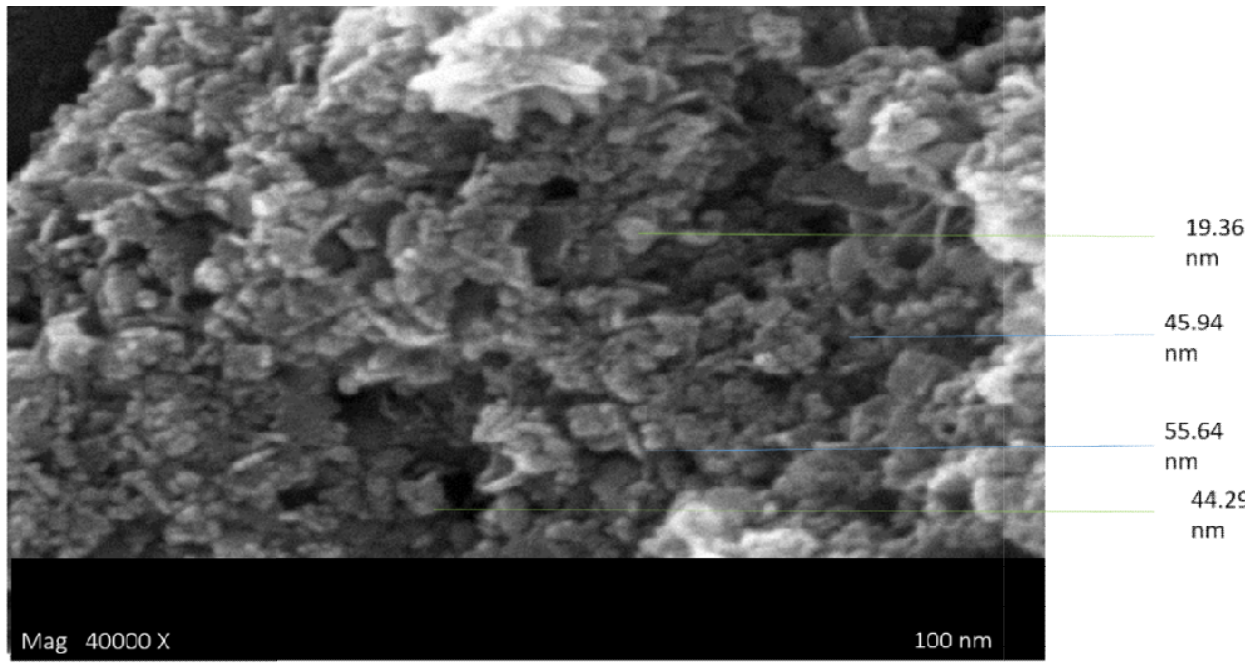

Figure 1: The above figure represents Scanning electron microscopy of Zinc Oxide Nanoparticle

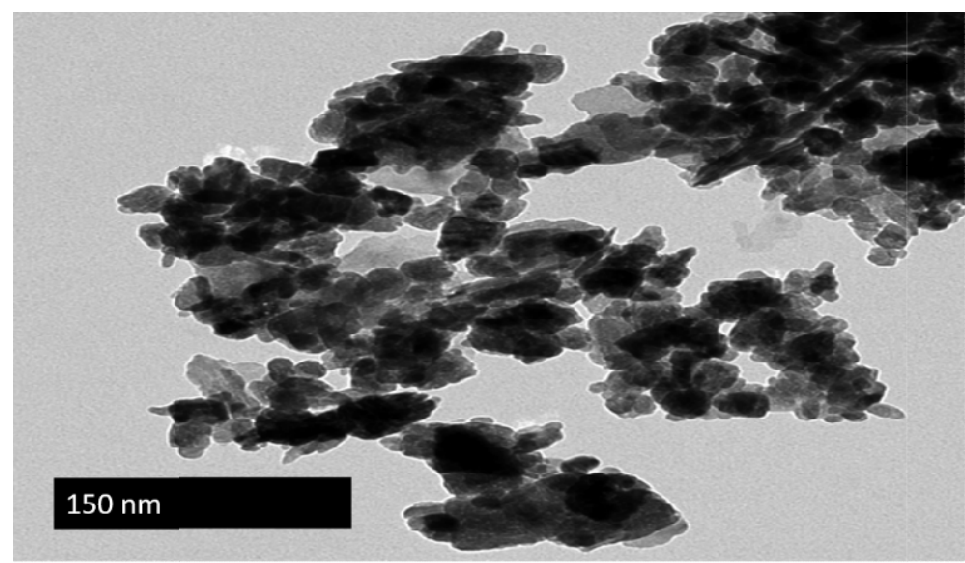

Figure 2 (a): The above figure represents the agglomeration of nanoparticles, the entire entity possessed the size of $150 \mathrm{~nm}$

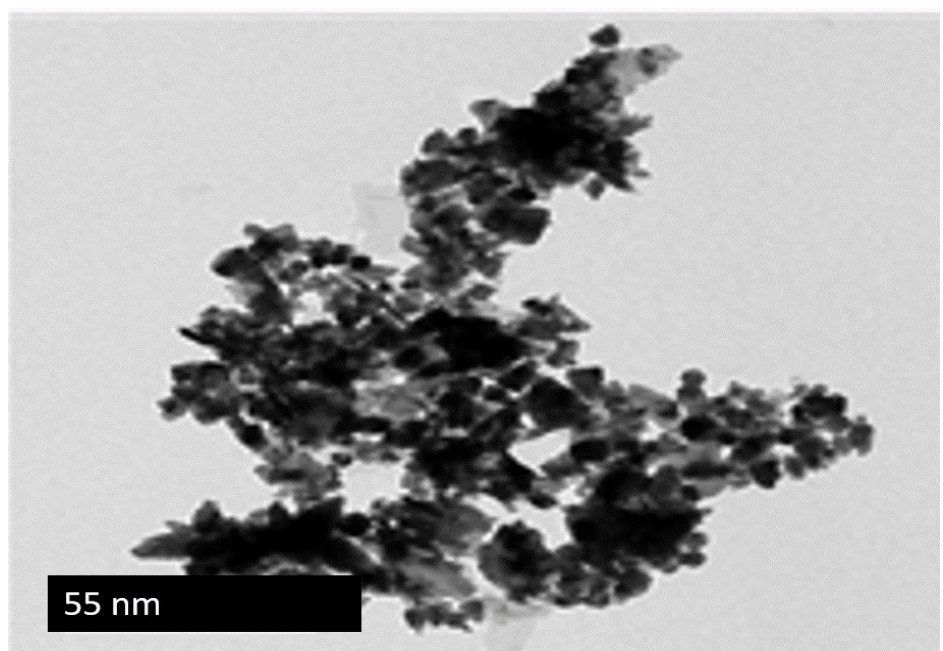

Figure 2 (b): The above figure represents the agglomeration of nanoparticles, the entire entity possessed the size of $55 \mathrm{~nm}$ 


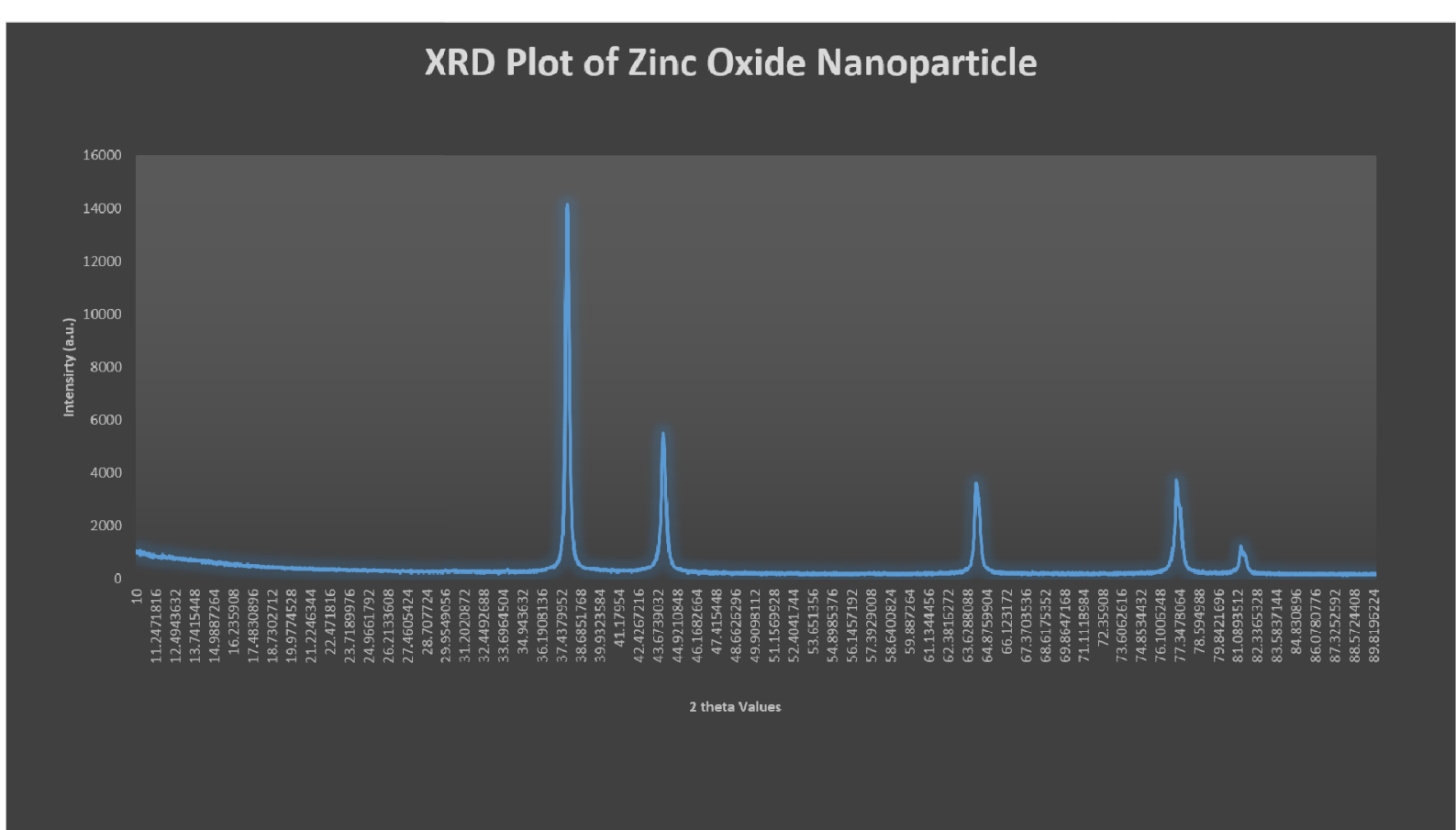

\section{CONCLUSION}

Figure 3: The above figure represents XRD of Zinc Oxide Nanoparticle

Patients with non-irresistible sickness who have remained in clinic have high hazard to obtain nosocomial contamination. It has been accounted for that, $10 \%$ medical clinic patients secure this contamination while remaining in emergency clinic [31]. [27, 29] have announced from their exploration that, nosocomial irresistible microscopic organisms showed least powerlessness to anti-infection agents and a portion of these microbes out appropriately created multidrug protection from these anti-infection agents. As of late from a 3-year follow-up concentrate in USA, Dowzicky and Park (2008) announced that, UTI bacterial pathogens have shown diminished weakness rates to tigecycline throughout the years.
Antibacterial property of silver nanoparticles would be the choice to beat the opposition issue.The examination intended to incorporate ZnONPs utilizing plant concentrate of Ocimum sanctum and investigate their adequacy in counteraction of biofilm arrangement for Klebsiella pneumoniae, Pseudomonas aeruginosa and Proteus morganii Expanding convergences of incorporated $\mathrm{ZnONPs}$ have been utilized from $50 \mu \mathrm{g} / \mathrm{ml}-200 \mu \mathrm{g} / \mathrm{ml}$ to research their viability in phyto amalgamated arrangement of biofilm by previously mentioned target life form. The outcomes indicated that these NPs could go about as promising competitors against these organisms of Urinary tract infection in future. Likewise, technique followed for combination of these NPs have 
been from plant source (Ocimum sanctum) as synthetic amalgamation of NPs have a few detriments over plant based NPs as announced in before work. Along these lines the examination infers that green combination of ZnONPs from Ocimum sanctum concentrate may assume a critical job against counteraction of biofilm development and at last prompting treatment of contaminations brought about by such biofilm framing microorganisms.

\section{Acknowledgment}

The authors gratefully acknowledge the necessary Laborarory facilities and constant supervision provided by the Department of Biotechnology, Rama University, Kanpur, U.P., and India for their generous support during the research work.

\section{REFERENCES}

[1] Albrecht MA, EvanCW, Raston, CL (2006). Green chemistry and the health implications of nanoparticles. Green chemistry. 3(8). 417-432.

[2] Kumar S., Polasa M, Shilpa C and Rao V (2015). Preparation and Characterization of Titanium Dioxide Nanoparticles by Polyvinylpyrrolidone Hydrothermal Processes. International Journal of Multidisciplinary Advanced Research Trends. 2 (1). 2349-7408.
[3] Catauro M, Raucci MG, De Gaaetano, F. and Marotta, A. 2004. Antibacterial and bioactive silvercontaining $\mathrm{Na} 2 \mathrm{O}$ × $\mathrm{CaO}$ × $2 \mathrm{SiO} 2$ glass prepared by sol-gel method. J. Mater Sci Mater Med. 15(7). 831837.

[4] Crabtree JH, Burchette RJ., Siddiqi Ra, IT, Huen Hadnott LL., Fishman A and Dial P. (2003) The efficacy of silver-ion implanted catheters in reducing peritoneal dialysis-related infections. Perit Dial Int. 23(4). 36874.

[5] Krolikowska A, Kudelski A, Michota A. andBukowska J.(2003). "SERS Studies on the Structure of Thioglycolic Acid Monolayers on Silver and Gold," Surface Science. 532-535: 227-232.

[6] Zhao G, Stevens J. (1998). Multiple parameters for the comprehensive evaluation of the susceptibility of Escherichia coli to the silver ion. Biometals. 11 (1). 27-32.

[7] Krishna B, Dan VG (2009). Silver nanoparticles for printable electronics and biological applications. Journal of materials research. 24(9). 2828-2836.

[8] Tripathi, RM, Saxena A, Gupta N, Kapoor H and Singh RP. (2010). 
Biological Synthesis of Silver

Nanoparticles by using Onion (Allium cepa) Extract and their Antibacterial Activity. Digest Journal of Nanomaterials and Bio-strucutres. 5(2). 427-433.

[9] Rodriguez-Sanchez L, Blanco. M.C and Lopez-Quintela MA (2000). Antibacterial and bioactive silvercontaining $\quad \mathrm{Na}_{2} \mathrm{O} \cdot \mathrm{CaO} \cdot 2 \mathrm{SiO}_{2}$ glass prepared by sol-gel method. Journal of Materials Science: Materials in Medicine.15 (7).831-837.

[10] Taleb C Petit, Pileni MP (1997). Synthesis of Highly Monodisperse Silver Nanoparticles from AOT Reverse Micelles: A Way to 2D and 3D Self-Organization. Chem. Mater. 9 (4). 950-959.

[11] Saxena A, Tripathi RM and Singh RP (2010.) Biological Synthesis of Silver Nanoparticles by using Onion (Allium Cepa) Extract and their Antibacterial Activity. Digest Journal of Nanomaterials and Biostructures. 5 (2). $427-432$.

[12] Rajiv P, Rajeshwari S. and Venckatesh R. (2013). BioFabrication of zinc oxide nanoparticles using leaf extract of Parthenium hysterophorus L. and its size-dependent antifungal activity against plant fungal pathogens, Spectrochimica Acta-Part A.112. 384-387.

[13] Anbukkarasi V, Srinivasan R. and Elangovan N (2015). Antimicrobial activity of green synthesized zinc oxide nanoparticles from emblica officinalis, Int. J. Pharm. Sci. Rev. Res. 33 (2). 110-115.

[14] Navale GR, Late DJ and Shinde SS. (2015). JSM Nanotechnology \&nanomedicine antimicrobial activity of $\mathrm{ZnO}$ nanoparticles against pathogenic bacteria and fungi. JSM Nanotechnol. Nanomed. 3(1). 1033-1041.

[15] Azizi S. Mohamad R, Bahadoran A, Bayat S, Rahim RA, Ariff A, Saad WZ (2016). Effect of annealing temperature on antimicrobial and structural properties of biosynthesized zinc oxide nanoparticles using flower extract of Anchusa italic. J. Photochem. Photobiol. B. 161. 441-449.

[16] Bhainsa KC, Souza D (2006). Extracellular biosynthesis of silver nanoparticles using the fungus Aspergillus fumigates. Colloids 
surface B Biosurfaces .47(2).160164.

[17] Sundrarajan M, Ambika S, Bharathi K. 2015. Plant-extract mediated synthesis of $\mathrm{ZnO}$ nanoparticles using Pongamia pinnata and their activity against pathogenic bacteria, Adv. Powder Technol.26.12941299.

[18] Saxena RS, Guptq B, Saxena KK, Singh RC and Prasad DNJ. (1984). Study of anti-inflammatory activity in the leaves of Nyctanthes arbor tristis Linn. An Indian medicinal plant. Ethnopharmacol.11 (3). 31930.

[19] Suresh V, Jaikumar S, Arunachalam (2013) Analgesic and AntiInflammatory Activities of the Methanolic Stem Bark Extract of Nyctanthes arbor-tristis Linn. Hindawi Publishing Corporation BioMed Research International.1.16.

[20] Awwadl AM, Salem NM, Amany O. and Abdeen (2012). Biosynthesis of Silver Nanoparticles using Olea europaea Leaves Extract and its Antibacterial Activity, Nanoscience and Nanotechnology. 2(6).164-170.
[21] Gunalan, S., Sivaraj, R. and Rajendran, V. 2012. Green synthesized $\mathrm{ZnO}$ nanoparticles against bacterial and fungal pathogens. Prog. Nat. Sci. 22.693700.

[22] Jitesh, S., RatheeA., Hassarajani SA. And Subrata C. (2007). Antioxidant activity of Nyctanthes arbor- tristis leaf extract. Food Chemistry. 103(4). 1350-1357.

[23] Khan ST,Musarrat $\mathrm{J}$ and AlKhedhairy AA(2016). Countering drug resistance, infectious diseases, and sepsis using metal and metal oxides nanoparticles: Current status, Colloids Surf. B 146, pp 70-83.

[24] Saxena RS, Gupta B. andLata S. (2002). Tranquilizing, antihistaminic and purgative activity of Nyctanthes arbor tristis leaf extract. J Ethnopharmacol. 81(3). 321-325.

[25] Shanmugasundaram T, Radhakrishnan M, Gopikrishnan V, PazhanimuruganR and Balagurunathan R. 2013. A study of the bactericidal, anti-biofouling, cytotoxic and antioxidant properties of actinobacterially synthesised 
silver nanoparticles. Colloids Surf.

B Biointer. 111. 680-687.

[26] Singh RP, ShuklaVK, Yadav RS, Sharma PK, Singh PK and Pandey AC. (2011). Biological approach of zinc oxide nanoparticle formation and its characterization. Advanced Material Letters 2(4), pp 313-317.

[27] Mirzaei H, Darroudi M. (2017). Zinc oxide nanoparticles: biological synthesis and biomedical applications, Ceram. Int. 43. 907914

[28] Lindau, S. T., Hoffmann, J. N., Lundeen, K., Jaszczak, A., McClintock, M. K., \& Jordan, J. A. (2009). Vaginal self-swab specimen collection in a home-based survey of older women: methods and applications. Journals of Gerontology Series B: Psychological Sciences and Social Sciences, 64(suppl_1), i106-i118.

[29] Yulizar, Y., Ariyanta, H. A., \& Abduracman, L. (2017). Green synthesis of gold nanoparticles using aqueous garlic (Allium sativum L.) Extract, and its interaction study with melamine. Bulletin of Chemical Reaction Engineering \& Catalysis, 12(2), 212-218.

[30] K. Khairan, Zahraturriaz and Z. Jalil green synthesis of sulphur nanoparticles using aqueous garlic extract (Allium sativum) Rasayan J. Chem Vol (12) 50-57.

[31] Mallikarjun, S., Rao, A., Rajesh, G., Shenoy, R., \& Pai, M. (2016). Antimicrobial efficacy of Tulsi leaf (Ocimum sanctum) extract on periodontal pathogens: An in vitro study. Journal of Indian Society of Periodontology, 20(2), 145.

[32] Kgatshe, M., Aremu, O. S., KatataSeru, L., \& Gopane, R. (2019). Characterization and Antibacterial Activity of Biosynthesized Silver Nanoparticles Using the Ethanolic Extract of Pelargonium sidoides DC. Journal of Nanomaterials, 2019. 